\title{
Kidney biopsy in very elderly patients: indications, therapeutic impact and complications
}

Mathilde Fedi ${ }^{1}$, Mickaël Bobot ${ }^{1,2}$, Julia Torrents ${ }^{3}$, Pierre Gobert ${ }^{4}$, Éric Magnant ${ }^{5}$, Yannick Knefati ${ }^{6}$, David Verhelst ${ }^{7}$, Gaëtan Lebrun ${ }^{8}$, Valérie Masson ${ }^{9}$, Philippe Giaime ${ }^{10}$, Julien Santini ${ }^{11}$, Stanislas Bataille ${ }^{10,2}$, Philippe Brunet ${ }^{1,2}$, Bertrand Dussol ${ }^{1,2}$, Stéphane Burtey ${ }^{1,2}$, Julien Mancini ${ }^{12}$, Laurent Daniel ${ }^{2,3}$ and Noémie Jourde-Chiche ${\text {, } 2^{*}}^{*}$

\begin{abstract}
Background: Few data is available on the risk/benefit balance of native kidney biopsy (KB) in very elderly patients.

Methods: Multicenter retrospective cohort study in the Aix-Marseille area: the results of KB and medical charts of all patients over 85 years biopsied between January 2010 and December 2018 were reviewed.

Results: 104 patients were included. Median age was 87 years. Indications for KB were: acute kidney injury (AKI) in $69.2 \%$ of patients, nephrotic syndrome (NS) with AKI in 13.5\%, NS without AKI in 12.5\%, and proteinuria in $4.8 \%$. Median serum creatinine was $262 \mu \mathrm{mol} / \mathrm{L}, 21 \%$ of patients required dialysis at the time of KB. Significant bleeding occurred in 7 (6.7\%) patients, requiring blood cell transfusion in 4 (3.8\%), and radiological embolization in 1 (1\%). The most frequent pathological diagnoses were: non-diabetic glomerular diseases (29.8\%, including pauci-immune crescentic glomerulonephritis in 9.6\%), hypertensive nephropathy (27.9\%), acute interstitial nephritis (16.3\%), renal involvement of hematological malignancy (8.7\%), and acute tubular necrosis (6.7\%). After KB, 51 (49\%) patients received a specific treatment: corticosteroids (41.3\%), cyclophosphamide (6.7\%), rituximab (6.7\%), bortezomib (3.8\%), other chemotherapies (3.8\%). Median overall survival was 31 months.
\end{abstract}

Conclusions: KB can reveal a diagnosis with therapeutic impact even in very elderly patients. Severe bleeding was not frequent in this cohort, but KB may have not been performed in more vulnerable patients.

Keywords: Kidney biopsy, Elderly patient, Advanced age, Acute kidney injury, Nephrotic syndrome, Glomerulonephritis, Pathology, Adverse events, Treatment, Survival

\section{Introduction}

As life expectancy increases, the proportion of elderly patients with renal diseases raises [1,2]: the medical care of elderly patients is changing in developed countries [3]. The life expectancy in France in 2019 was 85.6 years for women and 79.7 years for men. The median age of dialysis initiation was 70.9 years in 2018 [4] and $12.9 \%$

*Correspondence: noemie.jourde@ap-hm.fr

${ }^{2}$ Aix-Marseille Univ, C2VN, INSERM, INRAE, Marseille, France

Full list of author information is available at the end of the article of prevalent patients on chronic dialysis were older than 85 years.

Kidney biopsy $(\mathrm{KB})$ is an invasive diagnostic procedure aimed at identifying kidney diseases and guiding treatment to prevent progression to chronic kidney disease and end-stage kidney disease (ESKD). Nowadays, there is consensus of opinion that an age over 60-65 years is not a contraindication to kidney biopsy (KB) $[5,6]$ but the level of evidence for patients over $80-85$ years of age remains low. There is a general reluctance [7] to perform KB in very elderly patients due to the risk of complications 
(mostly bleeding) but these patients may also take full advantage of optimized therapeutic strategies [8-11].

To evaluate the risk/benefit balance of $K B$ in very elderly patients, we analyzed the indications, adverse events and therapeutic impact of KB in a cohort of consecutive patients over 85 years of age.

\section{Materials and methods}

In this retrospective multicenter cohort study, we analyzed the medical charts of all patients aged $\geq 85$ years who underwent a native kidney biopsy (KB) in 9 nephrology centers from the Aix-Marseille area between 2010 and 2018. The same pathologists (LD and JT), from the Laboratory of Pathology of the University Hospitals of Marseille (AP-HM), are in charge of all KB in this area (550 native KB each year), which allowed the screening of all cases.

All the procedures followed were in accordance with the Helsinki Declaration of 1975, as revised in 2000.

The French authority on data protection "Commission Nationale Informatique et Libertés" (CNIL) authorized data collection for this study (authorization number: 2211854).

For each case, clinical information was collected from the medical chart with the help of the referring nephrologist. Recorded data included:

- age, gender, history of hypertension, diabetes, progressive cancer or cardiovascular disease

- physical examination: blood pressure, edema, body mass index, extra-renal symptoms

- laboratory values: serum creatinine, estimated glomerular filtration rate (eGFR) using the MDRD formula, serum albumin, urine protein/creatinine ratio, presence of hematuria

- main indication for KB

- pathological diagnosis

- KB-related adverse events

- therapeutic intervention after KB

- kidney function evolution and date of dialysis initiation if applicable

- date of the last follow-up and date of death if applicable.

The following immunological tests were collected when available: antinuclear antibodies, anti-double-stranded DNA antibodies, anti-neutrophilic cytoplasmic antibody, anti-phospholipase A2 receptor (PLA2R) antibodies, rheumatoid factor, cryoglobulinemia, complement C3 and $\mathrm{C} 4$, and serum and urine electrophoresis. Serological tests for hepatitis B, hepatitis C, syphilis and HIV were also collected.
Indications for $\mathrm{KB}$ were classified as: acute kidney injury (AKI), nephrotic syndrome (NS), coexisting AKI and NS, proteinuria without AKI, and chronic kidney disease (CKD).

AKI was defined, according to the KDIGO guidelines, as an increase in serum creatinine of at least $26.5 \mu \mathrm{mol} / \mathrm{L}$ within $48 \mathrm{~h}$, or as an increase in serum creatinine to $\times 1.5$ time baseline [12]. NS was defined as a proteinuria $\geq 3.5 \mathrm{~g} /$ day with serum albumin $<3 \mathrm{~g} / \mathrm{dL}$. Significant proteinuria was defined as a urinary protein/creatinine ratio $\geq 0.5 \mathrm{~g} / \mathrm{g}$.

All KB were analyzed by the same renal pathologists (LD and JT), by light microscopy and immunofluorescence. For light microscopy, araldite-embedded sections were stained with Masson's trichrome and Jones silver impregnation ( 2 and $0.2 \mu \mathrm{m}$ sections respectively). For Immunofluorescence, $4 \mu \mathrm{m}$ frozen sections were incubated with anti-Immunoglobulins, C3, and C1q antibodies (The binding site, 1/50 dilutions, Birmingham, UK).

Descriptive statistics are presented as medians and interquartile ranges for continuous variables and as absolute values and percentages for categorical variables. The study endpoints were overall survival (OS) and renal survival, computed from the date of the biopsy to the date of the event (all-cause death for OS; all-cause death or dialysis for renal survival) or censored at the date of the last follow-up in event-free patients. Median survival rates were estimated using the Kaplan-Meier method. Hazard ratio were estimated using Cox regression model. All factors associated with outcomes in the univariate analyses ( $p$-value $<0.20)$ were fed into the multivariable models. All statistical tests were two-sided and the threshold for statistical significance was $p<0.05$. Analyses were performed using IBM SPSS Statistics 20.0 (IBM Inc., New York, USA).

\section{Results}

Between January 2010 and December 2018, a total of 114 very elderly patients underwent a native $\mathrm{KB}$ analyzed at the Laboratory of Pathology of AP-HM, which represents $2 \%$ of all native $\mathrm{KB}$ analyzed during the same period. Clinical data collection was insufficient for 10 patients, and 104 patients were included in this study. Follow-up data was available for 96 patients, who were considered in the survival analyses. The baseline characteristics of the study population are shown in Table 1.

The KB was performed during the course of a hospital stay in 73 patients, while 31 patients were hospitalized specifically for $K B$. The indications for $K B$ are shown in Fig. 1. AKI was the most common indication (69.2\% of patients), the other indications were NS with AKI (13.5\%), NS without AKI (12.5\%) and proteinuria (4.8\%). No patient had a KB for the exploration of CKD 
Table 1 Baseline characteristics of the elderly patients (aged $\geq 85$ years) included in this cohort. (Values are expressed as median [IQR] or number (\%))

\begin{tabular}{ll}
\hline & $\mathbf{N}=\mathbf{1 0 4}$ \\
\hline Age, years & $87[86-89]$ \\
Male & $64(61.5)$ \\
BMl, kg/m2 & $25[21-28]$ \\
Hypertension & $70(67.3)$ \\
Diabetes mellitus & $24(23.1)$ \\
Progressive cancer & $26(25.0)$ \\
Cardiovascular disease & $66(63.5)$ \\
Serum creatinine, $\mu m o l / L$ & $262[159-416]$ \\
eGFR, ml/min/1.73 m2 & $16[8-27]$ \\
Dialysis requirement & $22(21.2)$ \\
UPCR, g/g & $1.4[0.6-4.00]$ \\
Hematuria & $43(41.3)$ \\
Serum albumin, $\mathrm{g} / \mathrm{dL}$ & $28[21-52.5]$ \\
\hline
\end{tabular}

(BMI, body mass index; eGFR, estimated glomerular filtration rate; UPCR Urinary protein to creatinine ratio)

alone. Significant proteinuria was present in $87.5 \%$ of patients, abnormal immunological tests in $27 \%$, and extra-renal symptoms (mostly cutaneous lesions) in $17 \%$ of patients.

KB-related adverse events occurred in 7/104 (6.7, 95\%CI 2.8-13.4) patients and are detailed in Table 2. Four (3.8\%) patients required blood transfusion, including one patient for whom a radiological embolization was performed. No death was related to KB.
Pathological results are displayed in Table 3. Non-diabetic glomerular diseases were diagnosed in 31 (29.8\%) patients, including 10 (9.6\%) with pauci-immune crescentic glomerulonephritis. Hypertensive nephropathy was diagnosed in 29 (27.9\%) patients, and was the most frequent diagnostic in patients with proteinuria alone (4/5), as well as in patients with AKI (21/72) and in patients with NS and AKI (4/14). The most frequent diagnoses in patients with NS without AKI were membranous nephropathy (4/13 patients) and amyloidosis (AL or AA, 4/13 patients).

Overall, a disease likely to respond to a specific treatment was identified in 61 patients $(58.7,95 \%$ CI $48.6-$ 68.2\%): $56.9 \%$ (41/72) of patients with AKI, $71.4 \%(10 / 14)$ of patients with NS and AKI, 69.2\% (9/13) of patients with NS without AKI, and 20\% (1/5) of patients with proteinuria.

A specific therapy was administered to 51 patients (49, 95\%CI 39.1-59.0\%) following KB (Table 2), among whom: 6 patients with IgA nephropathy (including 3 Henoch-Schönlein purpura), 4 patients with minimal change disease or focal segmental glomerulosclerosis, and 13 patients with acute interstitial nephritis received corticosteroids; 9 patients with pauci-immune crescentic glomerulonephritis were treated with corticosteroids, associated with cyclophosphamide in 7 and with rituximab in 2; 3 patients with membranous nephropathy received rituximab; 1 patient received rituximab for B lymphoma with AL amyloidosis, and another 1 for membrano-proliferative GN; 4 patients received corticosteroids and bortezomib for AL amyloidosis $(n=1)$,

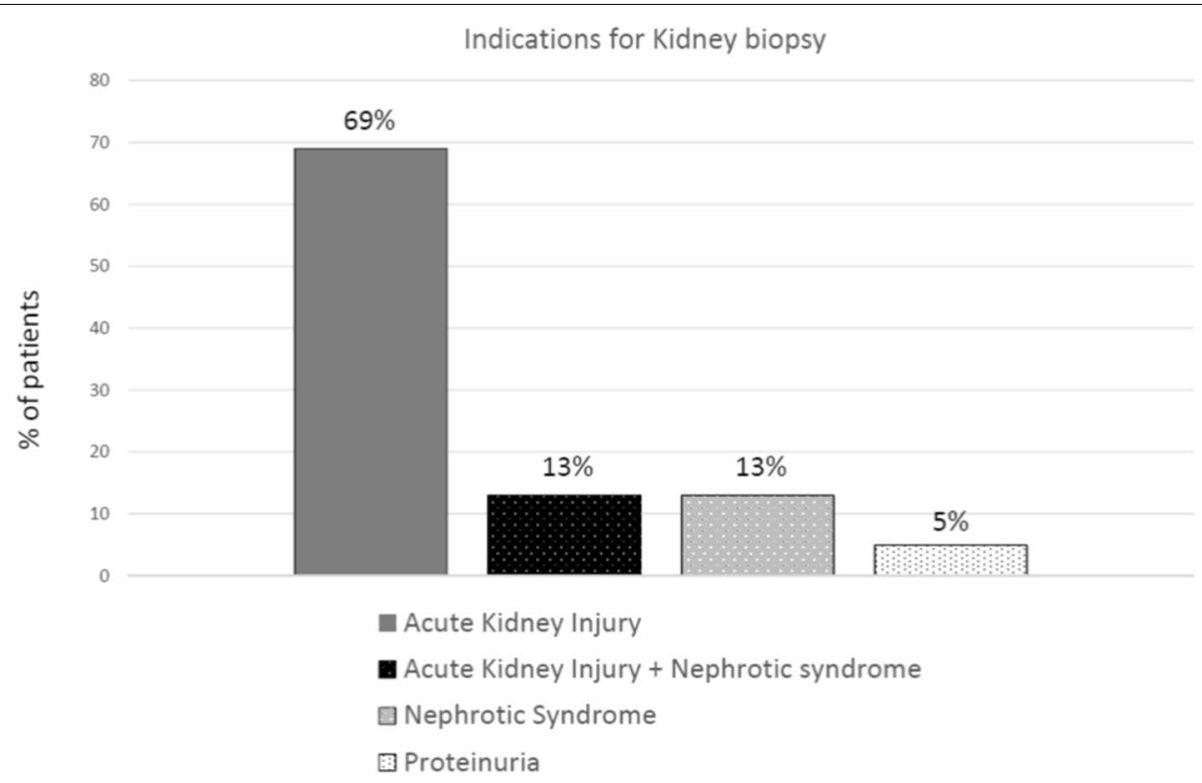

Fig. 1 Indication for kidney biopsy in the 104 very elderly patients. (AKI, acute kidney injury; NS, nephrotic syndrome; PU, proteinuria) 
Table 2 Kidney biopsy-related adverse events, and therapeutic impact of kidney biopsy

\begin{tabular}{ll}
\hline & $\mathbf{n}(\%)$ \\
\hline KB-related adverse events & $\mathbf{7}(\mathbf{6 . 7 )}$ \\
Mild bleeding or lumbar pain & $3(2.9)$ \\
Bleeding requiring blood transfusion & $3(2.9)$ \\
Bleeding requiring blood transfusion and radiological embo- & $1(0.9)$ \\
lization & \\
Therapeutic intervention after KB & $\mathbf{5 1 ( 4 9 . 0 )}$ \\
corticosteroids & $43(41.3)$ \\
IV cyclophosphamide & $7(6.7)$ \\
rituximab & $7(6.7)$ \\
bortezomib & $4(3.8)$ \\
Other chemotherapy & $4(3.8)$ \\
\hline
\end{tabular}

Table 3 Pathological diagnoses in the 104 native kidney biopsies

\begin{tabular}{lll}
\hline & $\mathbf{n}$ & $\mathbf{( \% )}$ \\
\hline Vascular diseases & $\mathbf{3 3}$ & $\mathbf{( 3 1 . 7 )}$ \\
Hypertensive nephropathy & 29 & $(27.9)$ \\
Cholesterol embolism & 2 & $(1.9)$ \\
Renal Infarction & 1 & $(1)$ \\
Scleroderma renal crisis & 1 & $(1)$ \\
Tubulo-Interstitial diseases & $\mathbf{2 5}$ & $\mathbf{( 2 4 )}$ \\
Acute interstitial nephritis & 17 & $(16.3)$ \\
Acute tubular necrosis & 7 & $(6.7)$ \\
Nephrocalcinosis & 1 & $(1)$ \\
Glomerular diseases & $\mathbf{3 1}$ & $\mathbf{( 2 9 . 8 )}$ \\
Pauci immune crescentic GN & 10 & $(9.6)$ \\
Membranous nephropathy & 6 & $(5.8)$ \\
IgA nephropathy & 6 & $(5.8)$ \\
embrano-proliferative GN & 3 & $(2.8)$ \\
Minimal change disease & 2 & $(1.9)$ \\
Focal segmental glomerular sclerosis & 2 & $(1.9)$ \\
AA amyloidosis & 2 & $(1.9)$ \\
Hematological diseases & $\mathbf{9}$ & $\mathbf{( 8 . 7 )}$ \\
AL amyloidosis & $\mathbf{9}$ & $(2.8)$ \\
Light chain deposition disease & 3 & $(1)$ \\
Myeloma cast nephropathy & 1 & $(1.9)$ \\
Light chain tubular inclusions (Fanconi) & 1 & $(1)$ \\
Leukemia (CMML) with blastic infiltration & 1 & $(1)$ \\
Lymphomatous infiltration (NHL) & 1 & $(1)$ \\
Nobetic kidney disease & $\mathbf{3}$ & $\mathbf{2} .9)$ \\
\hline & $\mathbf{3}$ & $\mathbf{2} .9)$ \\
\hline
\end{tabular}

GN Glomerulonephritis; CMML Chronic myelomonocytic leukemia; NHL NonHodgkin lymphoma myeloma cast nephropathy $(n=2)$ or monoclonal Ig light chain-associated Fanconi disease $(n=1)$.

Follow-up data were available for 96 patients ( 8 were lost to follow-up), their outcomes are displayed in Fig. 2. Median follow-up was 17 months (IQR 7-34 months), and follow-up ranged from 10 days (death of the patient) to 97 months. Sixteen (17\%) patients died within 6 months after KB. Among the 18 patients who were depending on dialysis at the time of $\mathrm{KB}, 3$ recovered and 1 died within 6 months. Among the 78 patients who were not on dialysis at the time of KB, 5 died within a month, 19 had a worsening of kidney function, 26 an improvement of kidney function, and 28 remained stable; 10 additional patients died within 6 months.

Overall survival is shown in Fig. 3A. Median overall survival was 32 months. Renal survival (composite survival: no death and no dialysis) is shown in Fig. 3B. Median renal survival was 19 months. Factors associated with overall and renal survival, by univariate and multivariate analyses, are detailed in Table 1 . Bleeding complications of KB and baseline cardiovascular disease were independently associated with impaired overall and renal survival. In addition, vascular kidney disease on $K B$ and baseline eGFR $<15 \mathrm{~mL} / \mathrm{min} / 1.73 \mathrm{~m}^{2}$ were independent predictors of impaired renal survival.

\section{Discussion}

We report here a large cohort of very elderly patients who underwent a native $\mathrm{KB}$ and show that the adverse events were not frequent and that the result of KB led to a specific therapeutic strategy in half of patients. In patients for whom no specific treatment was indicated, KB may have prevented the initiation of a potentially harmful treatment (such as corticosteroids). This work shows that for some patients, even if they are very old, the KB remains a useful procedure with therapeutic implications, especially in case of AKI and/or NS.

In the present cohort, the bleeding risk of $\mathrm{KB}$ was significant but not prohibitive (3\% requiring transfusion), without KB-related death. The same level of complication was identified in other series of elderly patients [13]. Even if lower rates of adverse events were reported in younger populations [14], several studies from the literature comparing the bleeding risks of $\mathrm{KB}$ in patients of different ages showed bleeding rates similar to the present cohort $[15,16]$. In previous studies, the baseline serum creatinine level has been reported to predict bleeding complications after $\mathrm{KB}$ [15]. Indeed, in the present cohort, all the patients with bleeding complications displayed AKI, and 3/7 were on dialysis. Halimi et al. [17], in a large national French retrospective cohort study published in 2020, reported a major bleeding after native $\mathrm{KB}$ in 2765 of 52,138 (5\%) patients (blood transfusions: 


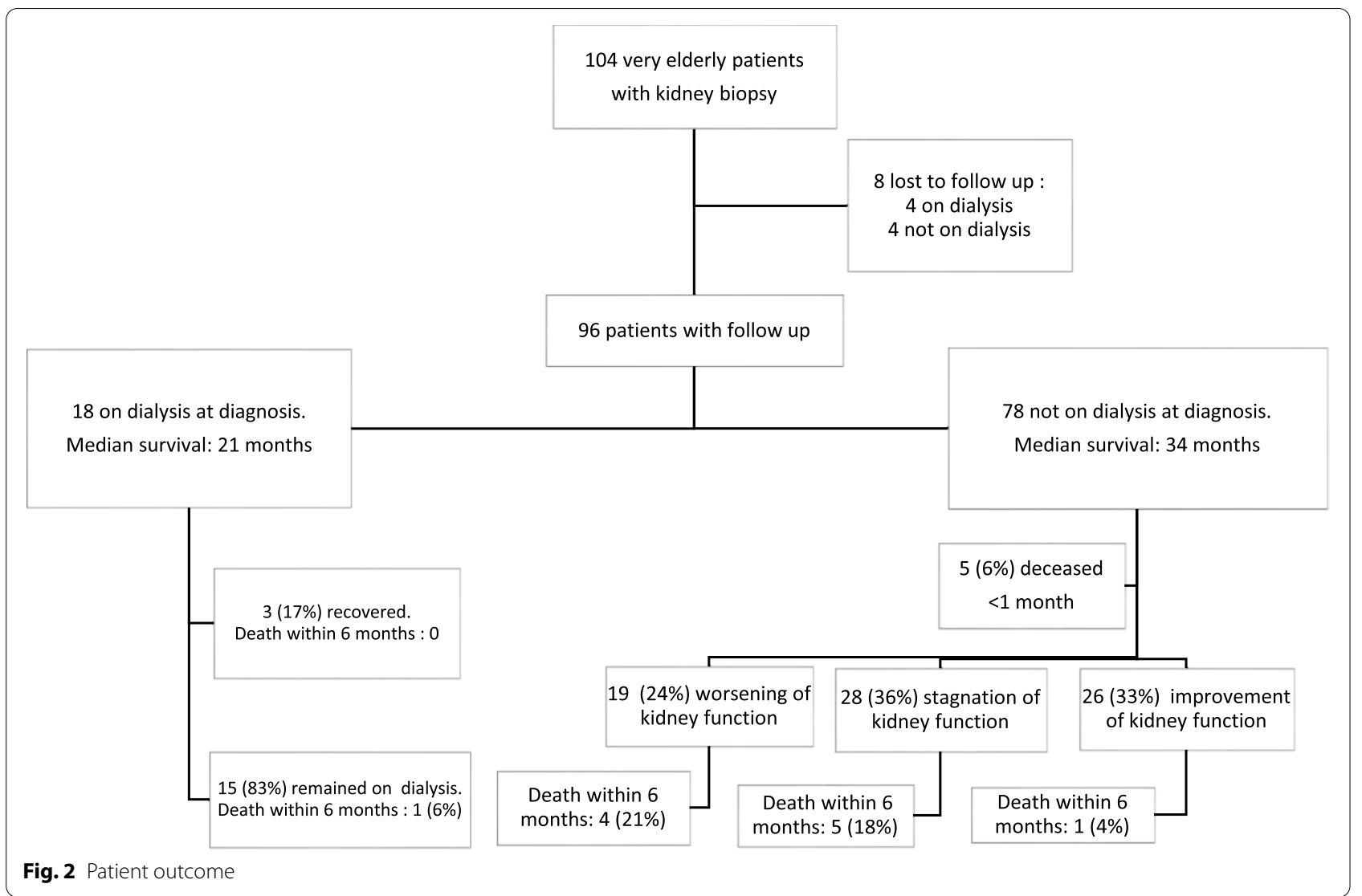

5\%; angiographic intervention: $0.4 \%$; and nephrectomy: $0.1 \%)$. Independent predictors of bleeding in this cohort were gender, frailty index, anemia, and altered kidney function. Advanced age was not an independent risk factor for bleeding in this large cohort.

Although patients were not selected in this retrospective study, an indication bias is likely in these very elderly subjects, as clinicians may have refrained from performing a $K B$ in the frailest patients or in patients with mild kidney involvement. This may explain why a large majority of patients from this cohort displayed AKI. The question of the futility of performing an invasive procedure such as KB in very old patients, whose life expectancy is probably limited, may arise. Yet, although their median age was 87 years, only $16.7 \%$ (16/96) of patients died within 6 months after KB. For comparison purposes, the 1-year survival rate for incident patients on dialysis is $68 \%$ in France [4].

The diagnostic benefit of $\mathrm{KB}$ in the very elderly has been reported before $[18,19]$. Moutzouris et al. [20] in an American cohort of 235 patients over 80 years of age, reported a therapeutic impact of KB in $67 \%$ of patients, particularly in those with AKI or NS. In the present cohort, the therapeutic impact of $\mathrm{KB}$ also depended on the indication for KB, patients with NS and/or AKI being the most likely to display a treatable condition, compared to patients with proteinuria alone.

AKI is associated with increased morbidity and mortality, especially in elderly subjects: the in-hospital mortality of elderly patients with AKI ranges from 15 to $40 \%$ [2024]. Pre-renal AKI, essentially due to volume depletion, and obstructive renal failure are the most common cause of AKI in elderly patients [23]. Shock, nephrotoxic drugs and rhabdomyolysis are also frequent causes of AKI. But when the clinical context is far from obvious, or when a glomerulonephritis is suspected, a KB may be useful even in elderly patients to guide the therapeutic strategy [24]. In the present cohort, as in other European cohorts $[19,25]$, AKI was the most common indication for KB in elderly patients. On the contrary, NS was the main indication for $\mathrm{KB}$ in different series of elderly patients from Asia (50\% of patients aged $\geq 80$ in Japan [26] $69 \%$ of patients aged $>80$ years in China [6]).

Acute interstitial nephritis (AIN) was the second most frequent diagnosis after hypertensive nephropathy in this cohort. Most AIN were immuno-allergic, related to the prescription of proton pump inhibitors, vitamin $\mathrm{K}$ antagonist or antibiotics, which are often prescribed in the 


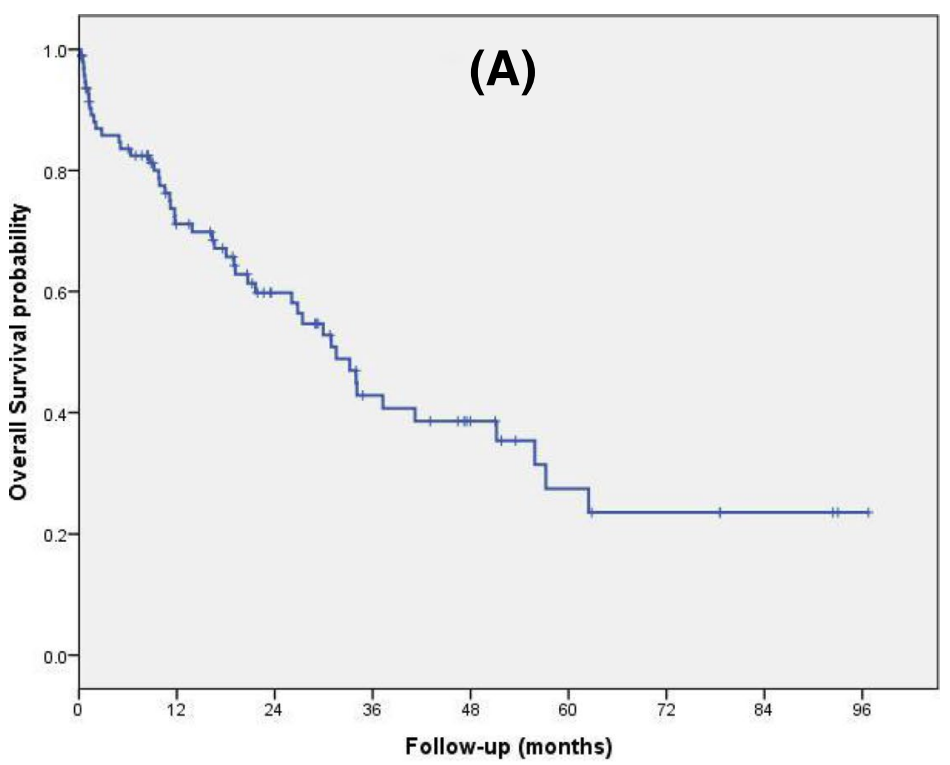

\begin{tabular}{|r|r|r|r|r|r|r|r|}
\hline Time & 0 & 6 months & 1 year & 2 years & 3 years & 4 years & 5 years \\
\hline number at risk & 96 & 74 & 54 & 35 & 19 & 13 & 6 \\
\hline \% surviving patients & 100 & 82 & 70 & 58 & 40 & 36 & 23 \\
\hline
\end{tabular}

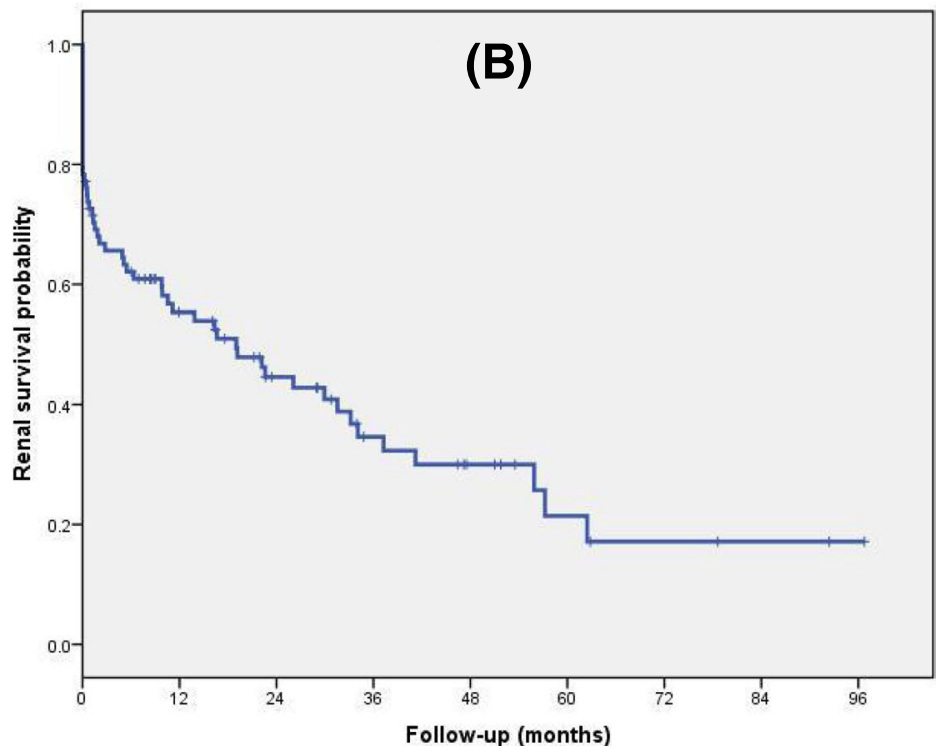

\begin{tabular}{|l|r|r|r|r|r|r|r|}
\hline time & 0 & 6 months & \multicolumn{1}{|c|}{1 year } & \multicolumn{1}{|c|}{ years } & 3 years & 4 years & 5 years \\
\hline number at risk & 96 & 52 & 39 & 24 & 14 & 10 & 4 \\
\hline \% surviving patients & 79 & 62 & 55 & 43 & 32 & 30 & 17 \\
\hline
\end{tabular}

Fig. 3 Kaplan Meier survival analyses. A) Overall survival. B) Renal survival 
Table 4 Factors associated with overall survival and renal survival

\begin{tabular}{|c|c|c|c|c|c|c|c|c|c|}
\hline & \multirow{2}{*}{$\begin{array}{l}\text { Univariate analysis } \\
\text { Variable }\end{array}$} & \multicolumn{4}{|c|}{ Univariate analysis } & \multicolumn{3}{|c|}{ Multivariable analysis } & \multirow[b]{2}{*}{$p$-value } \\
\hline & & Hazard ratio & $95 \% \mathrm{Cl}$ inf & $95 \% \mathrm{Cl}$ sup & $p$-value & Hazard ratio & $95 \% \mathrm{Cl}$ inf & $95 \% \mathrm{Cl}$ sup & \\
\hline \multirow[t]{23}{*}{ Overall Survival } & Gender Male & 1.1 & 0.6 & 2.0 & 0.701 & & & & \\
\hline & $\begin{array}{l}\text { Indication for KB: acute kidney } \\
\text { injury }\end{array}$ & 1.7 & 0.7 & 4.4 & 0.243 & & & & \\
\hline & Absence of specific treatment & & & & 0.360 & & & & \\
\hline & $\begin{array}{l}\text { Specific treatment other than } \\
\text { corticosteroids }\end{array}$ & 1.6 & 0.6 & 4.3 & 0.323 & & & & \\
\hline & $\begin{array}{l}\text { Specific treatment with corti- } \\
\text { costeroids }\end{array}$ & 0.8 & 0.4 & 1.5 & 0.467 & & & & \\
\hline & Age above 87 years & 1.0 & 0.6 & 1.8 & 0.958 & & & & \\
\hline & Acute kidney injury & 1.9 & 0.6 & 6.2 & 0.271 & & & & \\
\hline & Nephrotic syndrome & 1.0 & 0.6 & 1.9 & 0.882 & & & & \\
\hline & Proteinuria level & 0.9 & 0.5 & 1.7 & 0.755 & & & & \\
\hline & Glomerular kidney disease & 0.6 & 0.3 & 1.2 & 0.128 & NS & & & \\
\hline & $\begin{array}{l}\text { Tubulo-interstitial kidney } \\
\text { disease }\end{array}$ & 0.8 & 0.4 & 1.7 & 0.634 & & & & \\
\hline & Vascular kidney disease & 1.5 & 0.8 & 2.6 & 0.206 & & & & \\
\hline & $\begin{array}{l}\mathrm{eGFR}<15 \mathrm{ml} / \mathrm{min} / 1.73 \mathrm{~m} 2 \text { at } \\
\text { kidney biopsy }\end{array}$ & 1.6 & 0.9 & 2.9 & 0.106 & NS & & & \\
\hline & $\begin{array}{l}\mathrm{eGFR}<30 \mathrm{ml} / \mathrm{min} / 1.73 \mathrm{~m} 2 \text { at } \\
\text { kidney biopsy }\end{array}$ & 1.9 & 0.9 & 4.2 & 0.091 & NS & & & \\
\hline & Body mass index $<20$ kg/m2 & 1.0 & 0.3 & 3.3 & 0.982 & & & & \\
\hline & Serum albumin $<3 \mathrm{~g} / \mathrm{dL}$ & 0.9 & 0.4 & 1.8 & 0.732 & & & & \\
\hline & Haematuria & 1.3 & 0.7 & 2.3 & 0.358 & & & & \\
\hline & $\begin{array}{l}\text { Hospitalized specifically for } \\
\text { kidney biopsy }\end{array}$ & 0.7 & 0.4 & 1.4 & 0.361 & & & & \\
\hline & $\begin{array}{l}\text { Bleeding complications of } \\
\text { kidney biopsy }\end{array}$ & 2.8 & 1.1 & 7.3 & 0.034 & 3.2 & 1.2 & 8.2 & 0.019 \\
\hline & Diabetes & 0.8 & 0.4 & 1.6 & 0.529 & & & & \\
\hline & Hypertension & 0.6 & 0.3 & 1.1 & 0.109 & NS & & & \\
\hline & Current malignancy & 1.2 & 0.6 & 2.3 & 0.657 & & & & \\
\hline & Cardiovascular disease & 2.1 & 1.1 & 4.2 & 0.029 & 2.2 & 1.1 & 4.3 & 0.024 \\
\hline \multirow[t]{15}{*}{ Renal Survival } & Gender Male & 1.4 & 0.8 & 2.4 & 0.281 & & & & \\
\hline & $\begin{array}{l}\text { Indication for KB: acute kidney } \\
\text { injury }\end{array}$ & 4.2 & 1.3 & 13.5 & 0.016 & NS & & & \\
\hline & Absence of specific treatment & & & & 0.150 & NS & & & \\
\hline & $\begin{array}{l}\text { Specific treatment other than } \\
\text { corticosteroids }\end{array}$ & 1.2 & 0.5 & 2.9 & 0.700 & & & & \\
\hline & $\begin{array}{l}\text { Specific treatment with corti- } \\
\text { costeroids }\end{array}$ & 0.6 & 0.3 & 1.1 & 0.084 & NS & & & \\
\hline & Age above 87 years & 0.9 & 0.5 & 1.5 & 0.641 & & & & \\
\hline & Acute kidney injury & 3.0 & 0.9 & 9.7 & 0.061 & NS & & & \\
\hline & Nephrotic syndrome & 0.7 & 0.4 & 1.4 & 0.336 & & & & \\
\hline & Proteinuria level & 0.7 & 0.4 & 1.3 & 0.329 & & & & \\
\hline & Glomerular kidney disease & 0.5 & 0.3 & 1.0 & 0.035 & NS & & & \\
\hline & $\begin{array}{l}\text { Tubulo-interstitial kidney } \\
\text { disease }\end{array}$ & 1.1 & 0.6 & 2.0 & 0.731 & & & & \\
\hline & Vascular kidney disease & 1.6 & 0.9 & 2.8 & 0.085 & 2.1 & 1.1 & 3.8 & 0.020 \\
\hline & $\begin{array}{l}\mathrm{eGFR}<15 \mathrm{ml} / \mathrm{min} / 1.73 \mathrm{~m} 2 \text { at } \\
\text { kidney biopsy }\end{array}$ & 2.3 & 1.4 & 4.0 & 0.002 & 2.4 & 1.3 & 4.3 & 0.005 \\
\hline & $\begin{array}{l}\mathrm{eGFR}<30 \mathrm{ml} / \mathrm{min} / 1.73 \mathrm{~m} 2 \text { at } \\
\text { kidney biopsy }\end{array}$ & 1.8 & 0.9 & 3.7 & 0.080 & NS & & & \\
\hline & Body mass index $<20 \mathrm{~kg} / \mathrm{m} 2$ & 1.3 & 0.4 & 4.4 & 0.655 & & & & \\
\hline
\end{tabular}


Table 4 (continued)

\begin{tabular}{|c|c|c|c|c|c|c|c|c|}
\hline \multirow{2}{*}{$\begin{array}{l}\text { Univariate analysis } \\
\text { Variable }\end{array}$} & \multicolumn{4}{|c|}{ Univariate analysis } & \multicolumn{3}{|c|}{ Multivariable analysis } & \multirow[b]{2}{*}{$p$-value } \\
\hline & Hazard ratio & $95 \% \mathrm{Cl}$ inf & $95 \% \mathrm{Cl}$ sup & $p$-value & Hazard ratio & $95 \% \mathrm{Cl}$ inf & $95 \% \mathrm{Cl}$ sup & \\
\hline Serum albumin $<3 \mathrm{~g} / \mathrm{dL}$ & 0.8 & 0.4 & 1.5 & 0.442 & & & & \\
\hline Haematuria & 0.9 & 0.5 & 1.6 & 0.764 & & & & \\
\hline $\begin{array}{l}\text { Hospitalized specifically for } \\
\text { kidney biopsy }\end{array}$ & 0.6 & 0.3 & 1.1 & 0.111 & NS & & & \\
\hline $\begin{array}{l}\text { Bleeding complications of } \\
\text { kidney biopsy }\end{array}$ & 4.4 & 1.9 & 10.2 & 0.001 & 4.5 & 1.9 & 10.8 & $<0.001$ \\
\hline Diabetes & 0.7 & 0.3 & 1.3 & 0.205 & & & & \\
\hline Hypertension & 0.7 & 0.4 & 1.2 & 0.146 & NS & & & \\
\hline Current malignancy & 1.1 & 0.6 & 2.0 & 0.713 & & & & \\
\hline Cardiovascular disease & 2.5 & 1.3 & 4.6 & 0.005 & 2.1 & 1.1 & 3.9 & 0.025 \\
\hline
\end{tabular}

NS Not significant in multivariable analysis

elderly. In this condition, $\mathrm{KB}$ allows the withdrawal of the drug, and sometimes the prescription of corticosteroids.

Pauci-immune crescentic GN was the third most frequent diagnosis in this cohort. A high frequency of crescentic GN in elderly patients was also reported in several studies from different countries $(10 \%$ here, $14 \%$ in Spain [25] $11 \%$ in Japan [26] $13 \%$ in Italy [27]). KB is not always required for the diagnostic of ANCA-associated vasculitis. Yet, it can confirm the diagnosis in patients without ANCA or with atypical clinical presentation and indicate the presence of active proliferative lesions likely to benefit from immunosuppressive treatment. Indeed, immunosuppressive therapy can improve kidney function and systemic disease in ANCA-associated vasculitis, even in elderly patients [28]. In an American cohort of 78 patients over 80 years of age with biopsy-proven pauciimmune GN published in 2011 [9], the use of immunosuppressive therapy was associated with significantly lower risk of ESKD, death, and the combined outcome of ESKD or death.

KB can also be valuable for the diagnosis of haematological malignancies. In particular, AL amyloidosis without myeloma is not always detected on extra-renal tissue (such as minor salivary glands), and the detection of light chain amyloid deposits in a patient with NS can lead to the initiation of a chemotherapy which was not indicated on haematological parameters only. This was the case for 5 patients with hematological diseases from the present cohort.

There are some limitations to this study, in addition to its retrospective design. First, no data was available on the evaluation of frailty, autonomy and quality of life of the elderly patients included here. Second, no data was gathered on the clinical characteristics and outcomes of elderly patients with AKI and/or NS who were not proposed a KB. This hampers the evaluation of the "right indications for $\mathrm{KB}$ ” and of the benefit of $\mathrm{KB}$ in the global population of elderly patients.

Yet, the focus of this work on very elderly patients ( $\geq 85$ years), and the comprehensive analysis of $\mathrm{KB}$ indications, results, and therapeutic impact, together with the information on patients' outcomes, brings new information to the field.

In conclusion, this study provides detailed information on the benefits and risks of $\mathrm{KB}$ in a population of very elderly patients in France. The reasonable bleeding risk and the high proportion of pathological diagnoses with a therapeutic impact, especially in patients with AKI and/ or NS, pleads for the interest of this invasive procedure in some very elderly patients, irrespective of their age.

\section{Abbreviation \\ AKI: Acute kidney injury; AIN: Acute interstitial nephritis; BMI: Body mass index; CKD: Chronic kidney disease; CMML: Chronic myelomonocytic leukemia; ESKD: End-stage kidney disease; eGFR: Estimated glomerular filtration rate; GN: Glomerulonephritis; KB: Kidney biopsy; NHL: Non-hodgkin lymphoma; NS: Nephrotic syndrome; OS: Overall survival; PU: Proteinuria; UPCR: Urinary protein to creatinine ratio.}

\section{Acknowledgements}

We thank Laurent Samson for his help with the kidney biopsy register.

\section{Authors' contributions}

M.F., M.B., S.B., J.M. and N.J.C designed the study. M.F. acquired data, with the substantial help of P.G, E.M, Y.K, D.V, G.L, V.M, P.G, J.S, S.B., P.B and B.D. L.D and JT. performed the pathological examination of the kidney biopsies. M.F. wrote the first draft of the manuscript. S.B., M.B., J.T. and L.D. assisted in the interpretation of the results. J.M made the statistical analyses and prepared Figs. 3. N.J.C. revised the final manuscript. All authors read and approved the final manuscript.

\section{Funding}

The authors received no financial support for the research, authorship, and publication of this article.

\section{Availability of data and materials}

The datasets used and analysed during the current study available from the corresponding author on reasonable request. 


\section{Declarations}

\section{Ethics approval and consent to participate}

The French authority on data protection "Commission Nationale Informatique et Libertés" (CNIL) authorized data collection for this study (authorization number: 2211854). The need for informed consent was waived by the Commission Nationale Informatique et Liberté, who analyzed the study application and authorized data collection according to the French legislation, under the autorisation number 2211854.

\section{Consent for publication}

Not Applicable.

\section{Competing interests}

The authors declare that they have no competing interests.

\section{Author details}

${ }^{1}$ AP-HM, University Hospital of la Conception, Nephrology and Kidney Transplant Centre, Marseille, France. ${ }^{2}$ Aix-Marseille Univ, C2VN, INSERM, INRAE, Marseille, France. ${ }^{3} \mathrm{AP}-\mathrm{HM}$, University Hospital of La Timone, Anatomical Pathology Laboratory, Marseille, France. ${ }^{4}$ Rhône Durance Clinic, Medicine Department Avignon, Avignon, France. ${ }^{5}$ Private Hospital of Provence, Nephrology Department, Aix-en-Provence, France. ${ }^{6}$ Hospital of Sainte Musse, Nephrology Department, Toulon, France. ${ }^{7}$ Hospital Général Henri Duffaut, Nephrology Department, Avignon, France. ${ }^{8}$ Hospital of Aix en Provence, Nephrology Department, Aix-en-Provence, France. ${ }^{9}$ Polyclinic "des fleurs", Nephrology Department, Ollioules, France. ${ }^{10}$ Phocaean Institute of Nephrology, Bouchard Clinic, ELSAN, Marseille, France. ${ }^{11}$ Saint-Joseph Hospital, Nephrology Department, Marseille, France. ${ }^{12}$ Aix Marseille Univ, APHM, Inserm, IRD, SESSTIM, University Hospital of la Timone, BIOSTIC Service, Marseille, France.

\section{Received: 29 March 2021 Accepted: 10 August 2021}

Published online: 02 November 2021

\section{References}

1. Rule AD. The association between age and Nephrosclerosis on renal biopsy among healthy adults. Ann Intern Med. 2010;152:561.

2. Nie P, Chen R, Luo M, Dong C, Chen L, Liu J, et al. Clinical and pathological analysis of 4910 patients who received renal biopsies at a single Center in Northeast China. Biomed Res Int. 2019;2019:1-9.

3. Aucella F, Corsonello A, Leosco D, Brunori G, Gesualdo L, Antonelli-Incalzi R. Beyond chronic kidney disease: the diagnosis of renal disease in the elderly as an unmet need. A position paper endorsed by Italian Society of Nephrology (SIN) and Italian Society of Geriatrics and Gerontology (SIGG). J Nephrol. 2019;32:165-76

4. Le rapport du REIN 2018 est en ligne - Agence de la biomédecine [Internet]. 2020. https://www.agence-biomedecine.fr/IMG/pdf/rapport_rein_ 2018 v2.pdf.

5. Sevillano AM, Diaz M, Caravaca-Fontán F, Barrios C, Bernis C, Cabrera J, et al. On behalf of the Spanish Group for the Study of Glomerular Diseases (GLOSEN): IgA nephropathy in elderly patients. Clin J Am Soc Nephrol. 2019;14:1183-92.

6. Xiong M, Wang L, Liu X, Yue S, Dong J, Li Y, et al. Kidney Biopsies in Elderly Chinese Patients: A Nationwide Survey PMID: 32362418. https://doi.org/ 10.1053/j.ajkd.2020.02.438.

7. Luciano RL, Moeckel GW. Update on the native kidney biopsy: Core curriculum 2019. Am J Kidney Dis. 2019;73:404-15.

8. Planchais M, Brilland B, Demiselle J, Besson V, Duveau A, Croué A, et al Renal biopsy in very elderly patients (over 80 years): clinical presentation, histological diagnosis, and long-term outcome. Int Urol Nephrol. 2020;52:721-9.
9. Bomback AS, Appel GB, Radhakrishnan J, Shirazian S, Herlitz LC, Stokes B, et al. ANCA-associated glomerulonephritis in the very elderly. Kidney Int. 2011:79:757-64.

10. Dhaun N, Bellamy CO, Cattran DC, Kluth DC. Utility of renal biopsy in the clinical management of renal disease. Kidney Int. 2014:85:1039-48.

11. Yoon HE, Shin MJ, Kim YS, Choi BS, Kim BS, Choi YJ, et al. Clinical impact of renal biopsy on outcomes in elderly patients with nephrotic syndrome. Nephron Clin Pract. 2011;117:c20-7.

12. Notice. Kidney Int Supp/ 2: 1, 2012.

13. Uezono S, Hara S, Sato Y, Komatsu H, Ikeda N, Shimao Y, et al. Renal biopsy in elderly patients: a Clinicopathological analysis. Ren Fail. 2006:28:549-55.

14. Bataille S, Jourde N, Daniel L, Mondain J-R, Faure M, Gobert P, et al. Comparative safety and efficiency of five percutaneous kidney biopsy approaches of native kidneys: a multicenter study. Am J Nephrol. 2012;35:387-93.

15. Whittier WL, Korbet SM. Timing of complications in percutaneous renal biopsy. J Am Soc Nephrol JASN. 2004;15:142-7.

16. Parrish AE. Complications of percutaneous renal biopsy: a review of 37 years' experience. Clin Nephrol. 1992;38:135-41.

17. Halimi J-M, Gatault P, Longuet H, Barbet C, Bisson A, Sautenet B, et al. Major bleeding and risk of death after percutaneous native kidney biopsies: a French nationwide cohort study. Clin J Am Soc Nephrol CJN. 2020;14721219. https://doi.org/10.2215/CJN.14721219.

18. Kitterer D, Gürzing K, Segerer S, Alscher MD, Amann K, Braun N, et al. Diagnostic impact of percutaneous renal biopsy. Clin Nephrol. 2015:84(2015):311-22.

19. Nair R, Bell JM, Walker PD. Renal biopsy in patients aged 80 years and older. Am J Kidney Dis. 2004:44:618-26.

20. Moutzouris D-A, Herlitz L, Appel GB, Markowitz GS, Freudenthal B, Radhakrishnan J, et al. Renal biopsy in the very elderly. Clin J Am Soc Nephrol. 2009:4:1073-82.

21. Li Q, Zhao M, Du J, Wang X. Outcomes of renal function in elderly patients with acute kidney injury. Clin Interv Aging. 2017;12:153-60.

22. Akposso K, Hertig A, Couprie R, Flahaut A, Alberti C, Karras GA, et al. Costa De Beauregard MA, Lahlou a, rondeau E, Sraer JD: acute renal failure in patients over 80 years old: 25 -years' experience. Intensive Care Med. 2000:26:400-6

23. Liu J-Q, Cai G-Y, Liang S, Wang W-L, Wang S-Y, Zhu F-L, et al. Characteristics of and risk factors for death in elderly patients with acute kidney injury: a multicentre retrospective study in China. Postgrad Med J. 2018;94:249-53.

24. Coca SG. Acute kidney injury in elderly persons. Am J Kidney Dis Off J Natl Kidney Found. 2010:56:122-31.

25. Verde E, Quiroga B, Rivera F, López-Gómez JM. Renal biopsy in very elderly patients: data from the Spanish registry of glomerulonephritis. Am Jephrol. 2012;35:230-7.

26. Yokoyama H, Sugiyama H, Sato H, Taguchi T, Nagata M, Matsuo S, et al. Renal disease in the elderly and the very elderly Japanese: analysis of the Japan Renal Biopsy Registry (J-RBR). Clin Exp Nephrol. 2012;16:903-20.

27. Rollino C, Ferro M, Beltrame G, Quattrocchio G, Massara C, Quarello F, et al. Renal biopsy in patients over 75: 131 cases. Clin Nephrol. 2014:82(2014):225-30.

28. Jefferson JA. Treating elderly patients with ANCA-associated Vasculitis. Clin J Am Soc Nephrol. 2015:10:1110-3.

\section{Publisher's Note}

Springer Nature remains neutral with regard to jurisdictional claims in published maps and institutional affiliations. 